\title{
Online support material for Computer Science Honours program using Blackboard
}

\author{
Regina Berretta \\ School of Electrical Engineering and Computer Science \\ The University of Newcastle \\ Newcastle, Australia \\ e-mail: Regina.Berretta@newcastle.edu.au
}

\author{
Helen Giggins \\ School of Electrical Engineering and Computer Science \\ The University of Newcastle \\ Newcastle, Australia \\ e-mail: Helen.Giggins@newcastle.edu.au
}

\begin{abstract}
In this paper we present the outcomes of a project aimed to provide online support material to help students to become more familiar with the Computer Science Honours program at The University of Newcastle. We discuss the motivation behind the decision to present the material via a Learning Management System. These systems are traditionally designed to deliver course material online. We propose a new use for Learning Management Systems, whereby material is organized and presented to inform Computer Science students about the Honours program and consequently give them extra encouragement to undertake the Honours program. Additionally, for students that are already enrolled in the program, online support material is made available to help them during the course of their studies.
\end{abstract}

Keywords: Learning Management System, Blackboard, Honours.

\section{INTRODUCTION}

The past fifteen years has spawned a technological revolution in our universities and in society at large. In particular, the Internet and the World Wide Web (WWW) now permeate our every day interactions and communications. Today, most students entering into the higher education sector use the Internet to research, study and communicate with friends. They belong to a generation that grew up surrounded by digital technology [1] and many of them believe that everything they need to know is available from the Internet [2]. Clearly there has been a shift in student expectations, although the level to which these changes will impact on teaching and learning is still up for discussion [3]. However, there is no denying that the adoption of the Internet as a research tool has become mainstream in society, particularly with young adults [4]. Consequently, students mainly use the information available online to understand and sometimes make decisions about several topics. Teenagers, for example, generally use the information found on the Internet to compare and contrast the different university programs available and make their final choice based on that search process. Consequently, the way in which university webpages are designed can have a large impact on the decision a student makes about a specific program and/or institution. Many universities already provide a lot of information about the different programs offered via their webpages, although in many cases it could be in a more attractive format for prospective students.

In addition to their standard webpages, most universities today use some form of Learning Management Systems (also known as Course Management Systems) to deliver course materials online. An OECD survey conducted in 2004 showed that $79 \%$ of institutions in Australia had already fully implemented a LMS, such as Blackboard ${ }^{1}$ or WebCT, and this number was set to rise to $95 \%$ within 12 months [5, p.128]. This figure demonstrates the level of investment that universities have committed, both in terms of money and time. The utilisation of Learning Management Systems (LMS) is having a large impact on teaching and learning in higher education and the investigation of the consequences of such tools is just starting. Some of the potential benefits of such systems include, an increase in the efficiency of teaching, an enriched learning environment, meeting student's technological and flexibility needs and allowing institutions to compete in the current educational marketplace while managing the teaching and learning process[6].

Although there has already been much debate about the relative merits of such systems, the objective here is not to investigate the consequences of the intense use of LMS by universities, but instead show a different yet complementary use. Namely that of providing students with information for Honours programs generally, and more specifically for the Computer Science Honours program at The University of Newcastle. There is an existing framework within the university for providing information and support material for Honours students, however, we feel that there are certain limitations to the current mode of delivery, both for students and academics. We seek to employ the use of LMS as a alternative to traditional websites in this context.

This paper presents the development of Blackboard areas to provide resources and information to students in a way that complements the current university website. The remainder of this paper is organised as follows. We first discuss how technology impacts on the way students learn and research. We next examine how other Australian universities present their Computer Science Honours, and contrast this to the way in which it is done at The University

$\underline{\text { www.blackboard.com }}$

$\overline{978-1-4244-4520-2 / 09 / \$ 25.00 ~ @ 2009 ~ I E E E ~}$ 


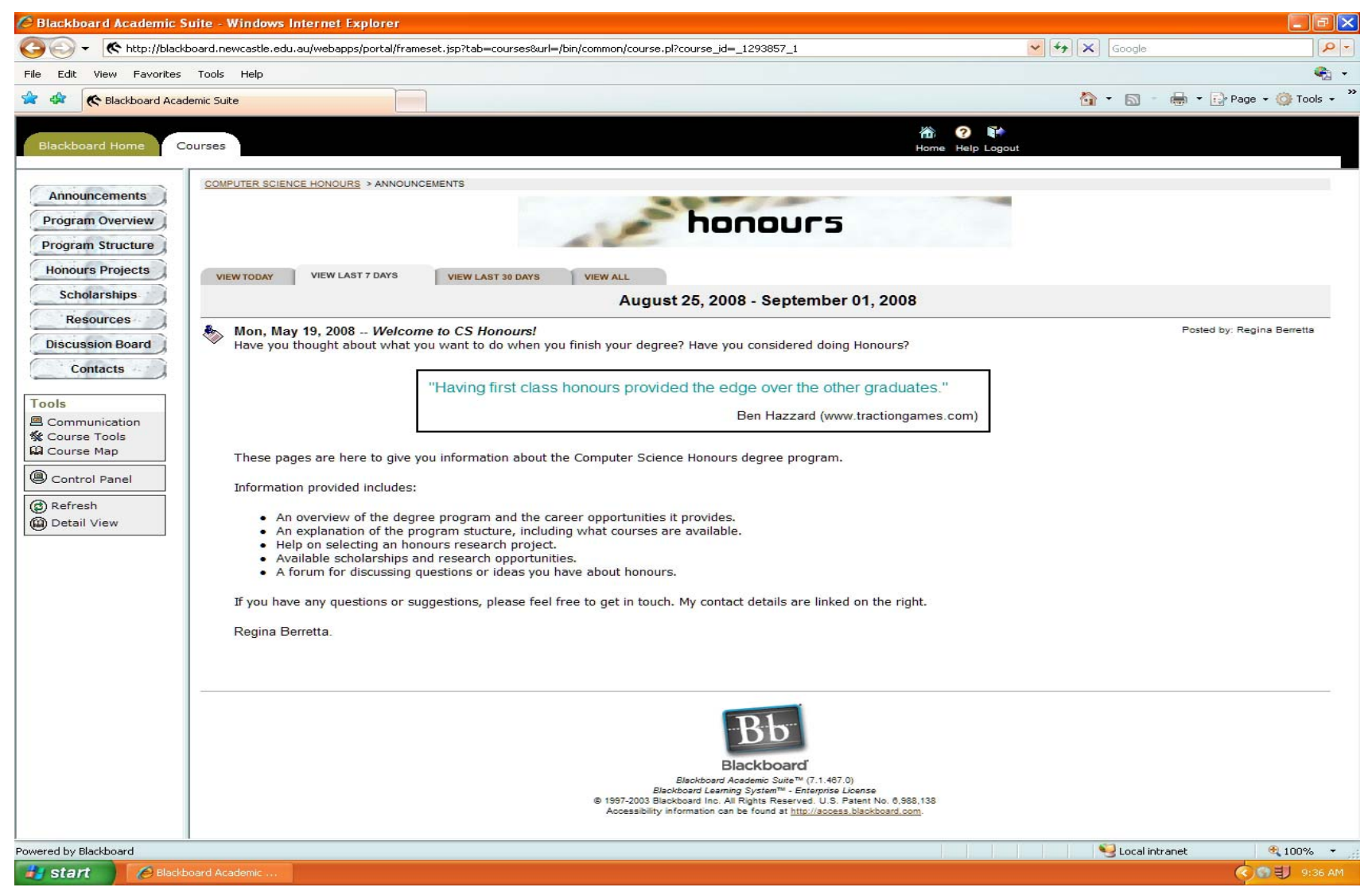

Figure 1. Home Page - Computer Science Honours information area

of Newcastle. Finally, we examine our efforts at developing several areas for Computer Science Honours within a LMS, with the aim of improving the quality of the online information about the Computer Science Honours program, in a format that students are more comfortable with.

\section{How to AtTRACT 'Digital Natives'}

It would seem clear that the pervasive adoption of technology by the current generation will have far reaching impacts on teaching and learning outcomes, both now and into the future. It would also seem clear that universities must move away from their traditional methods of recruiting students to better attract this new group of technologically proficient students.

Prensky [1] has provided us with a useful term for this generation of students born post 1982, that of 'digital natives'. The name comes from the idea that this generation, more so than any before it, has become fluent in the language of technology. They are described as having grown up "surrounded by and using computers, videogames, digital music players, video cams, cell phones, and all the other toys and tools of the digital age" [1, p.1]. This immersion in technology has thus been linked to a change in mindset, and even a fundamentally different way of thinking [7]. The qualities ascribed to this group include multitasking, connected, social, intuitive visual communicators and immediate [8].
Despite the wide-spread support for the views of Prensky and his peers, there have been recent calls for more thorough debate and analysis of both the conclusions drawn and the impact they have on teaching and learning [3]. As Bennett, Maton and Kervin point out, there is little evidence to support the idea of a "homogenous generation with technical expertise and a distinctive learning style" [3, p.780]. This notion can in fact have a more significant impact for educators since it means that there is a large variation in the computing and technology skills of students. It is imperative that educators do not make the assumption that all students fit into the 'tech-savvy' mold presented by Prensky [1], as they will risk alienating the remainder of students.

Regardless of whether or not academics agree with the notion of 'digital natives', it would still seem clear that there has been a paradigm shift in the way students, both young and old, tend to want to access their information.

A recent survey of first-year Australian University students [4] appears to support some of these claims. Results showed that around $90 \%$ of students had unrestricted access to a desktop computer, and over $60 \%$ had similar access to a laptop, with only $0.6 \%$ of students having access to neither [4]. Over $93 \%$ of students indicated that they wished to have access to the Internet to search for information, and around $81 \%$ indicated that they wanted access to a LMS [4]. These figures support our assumption that Internet tools are frequently used by students as a teaching and learning tool. For universities to best market themselves to this generation 
of students, they need to present information in a way that most appeals to them. Currently many institutions provide good quality information to students, yet it is advantageous for them to also provide complementary information in a format that students will find more appealing.

\section{Promoting COMPUTER SCIENCE HoNOURS}

Being interested in how Computer Science Honours programs were being promoted, we looked at the websites of twelve Australian universities, paying particular attention to how they presented this program and how easy it was to navigate to the information. The universities investigated were: The Australian National University, The University of New South Wales, The University of Wollongong, Macquarie University, The University of Sydney, The University of Queensland, The University of Melbourne, The University of Western Australia, Flinders University, James Cook University, The University of Adelaide and Monash University.

One of the clear problems with many of the university websites was the difficulty in navigating to any appealing information on their Computer Science Honours programs. Even if a site was easily navigated, many provided a poor design within the actual page/s, making it difficult for students to glean attractive information. While some sites had reasonable design, the quality of the information provided was lacking to some degree. In some cases insufficient information was provided to allow a student to make an informed decision about both the content and quality of the program on offer. One of the stand-out sites warranting special mention is that of The University of New South Wales ${ }^{2}$ the site is easy to navigate and offers a wealth of information in a pleasant and easy to read format. Additionally, the site has different sections to provide specialised information for prospective and current students.

Having looked at what design and information other Universites employed in presenting their Computer Science Honours program, we turned our attention back to our own institution, The University of Newcastle ${ }^{3}$, with the navigation path being as follows. The different programs offered by The University of Newcastle can be found in the 'program finder' link in from the main university webpage. If a student would like to know about Computer Science Honours program they can find the information in a specific webpage, where they will find a very short description of the program and the courses that the student should undertake, among other policy details. Most of the courses are only described by the title 'Special Topics' and details of the content are not presented. One of the main drawbacks of this page is that it does not explain the different projects areas that the student could choose for their major project, nor does it have links to the pages of the different available supervisors and their research areas of expertise.

\footnotetext{
${ }^{2}$ The University of New South Wales -http://www.unsw.edu.au

${ }^{3}$ The University of Newcastle - http://www.newcastle.edu.au
}

\section{The USE OF LeARnING MANAGEMENT Systems - BLACKBOARD}

Having realised that there were shortcomings in the way in which information is currently provided to prospective and current Computer Science Honours students at The University of Newcastle, we set out to design a new delivery system. The first decision was to choose if it would be better to make changes in the university webpage or use a Learning Management System. The first constraint about changing the university webpages is the lack of control and maintenance that an academic has in the University of Newcastle. The webpage mentioned before is derived from a standard template for every program and an academic is not allowed to make substantial changes to it. Another possibility would be to make a webpage with a link from the Faculty or School webpage. However, after the student goes to "program finder', there is no reason to believe that the student would find this specific webpage. In addition, a new webpage would not trigger the curiosity of a student.

The second option was to use LMS, in this case, Blackboard. The LMSs were initially designed to deliver courses for distance education [9]. Today they are widely used to complement (or as a supplement to) the traditional face-to-face teaching for every single course in most universities in Australia. Basically, LMSs are used to deliver course materials available to students and online discussion, but they can support an extensive range of teaching and learning activities. The course materials can be organized in different ways to enhance the engagement between the student and the course material, since it is a significant element for student learning [10]. A number of traditional ways to use LMSs can be found in [11], [12].

The plan in this project was to develop two areas in Blackboard. The first one is the 'Computer Science Honours information area' which every student enrolled in Computer Science would have access to it. This area briefly describes the Computer Science Honours program in a more informal language. It shows testimonials from previous students, the advantages of such a program, a description of different projects with links to academics and/or research groups in our discipline, links to articles of interest, etc. The second one is the 'Computer Science Honours project area' for students currently enrolled in the Computer Science Honours program. This area is more specifically designed to help the student develop their honours project, with a detailed description of each milestone, including requirements, expectations and assessment criteria. Below, a brief description of how each Blackboard area is organized.

\section{A. Computer Science Honours Information Area}

This Blackboard area is designed to be available for all Computer Science students, from first year onwards. The site is broken up into eight different sections (see Figure 1). As with most standard Blackboard courses by default, the students are provided with Announcements, Contacts, and Discussion Board areas. In addition, we provide more specific links relevant to the content, which we now discuss individually in more detail. 
Program Overview. This area provides a short and informal description of the program and includes testimonials from previous students and a list of general fields presented within the program. It also provides students with useful career advice, designed to highlight the advantages of undertaking the Computer Science Honours program.

Program Structure. This area outlines the exact structure of the program, including what is expected from the student in each semester. It also gives short and informal description of each course offered in the current year, and an archive of courses offered in previous years. A reminder that this lack of detail was a serious deficiency of the current information provided on the formal university site.

Honours Projects. Here we provide a description of project areas that could be undertaken by a student commencing the Computer Science Honours program. Details of the research areas of each academic in the discipline is provided, along with information on specific research topics they have tailored to the Computer Science Honours program. Students are encouraged to contact academics directly to discuss projects that are not specifically listed, but might be in the scope of interest for that academic.

Scholarships. Available opportunities for scholarships are provided, with links to scholarships both at faculty and university level. This area is also designed to allow academics to advertise various summer scholarships or short term research projects that might be available to Computer Science Honours students.

Resources. This area is designed to provide the students with useful resources, particularly in helping them to make a decision as to whether or not embark on the Computer Science Honours program. It includes articles, papers, links that are related with computer science, different career paths, and opportunities related to postgraduate study.

By allowing students from all levels of the Computer Science program to have access to this site, we hope to foster a connection between undergraduate and Computer Science Honours programs, and further encourage students to continue into postgraduate studies. The hope is that students already undertaking the Computer Science Honours program will provide feedback and encouragement to students who had not previously considered undertaking this program.

\section{B. Computer Science Honours Project Area}

Further to the general information area discussed previously, we also aim to provide a Blackboard area only for students currently enrolled in the Computer Science Honours program. The goal of this area is to provide students with very specific resources and to also foster a community spirit amongst the group. Much of the information is already available in other areas of the university website, but we seek to provide students with a 'one-stop-shop' for all the information they require in their Computer Science Honours year.

The structure of the Computer Science Honours program at The University of Newcastle is as follows. Students are required to complete 50 units (credit points) of undergraduate courses at fourth year level. Additionally, students undertake a full year 'Honours Project' under the guidance of an academic supervisor. The project has three main deliverables: an initial research proposal to outline the workto be undertaken, a seminar presented at the end of the first semester, and a project thesis provided at the completion of the Honours program.

The Blackboard area for the Computer Science Honours project has the following content. As per the general site, students are provided with Announcements, Staff Information and a Discussion Board area. The additional features of this site are now discussed in more detail.

Course Outline. This area is designed to deliver the official outline of the course, including links to offical university policies and sites.

Getting Started. This important area provides a brief description of the steps the student should take in the beginning of the program. The students are encouraged to finalise their project supervision and understand what is expected of them during the course of the year. They are also advised to arrange regular meetings with their honours project supervisor and given useful tips on how best to manage their relationship with their supervisor. Finally, they are advised to finalise their course selection, and given a link to descriptions of the various courses on offer.

Project Proposal. Here we outline the specific requirements, expectations and assessment criteria for the project proposal. Students are expected to submit a fairly detailed proof of concept for their project early in the year. This section will have useful resources to help students complete this task effectively.

Project Seminar. This area provides students with the requirements, expectations and assessment criteria for their project seminar. The student is expected to present a seminar for the project proposal before the end of the first semester of their enrollment, with the intention of supplying the student with feedback on their project and oral presentation skills. We provide resources and guidance for students on how best to prepare a research presentation.

Project Thesis. This area outlines the requirements, expectations and assessment criteria for the project thesis, a major component of the student's assessment in the Computer Science Honours program. Since the preparation of the thesis is generally such a new process for students, we aim to provide them with many resources on how to prepare and present their research outcomes.

Web Resources. The main aim of this section is to provide links to resources that can help the student develop the 
various components of their Computer Science Honours project, as outline above. Many of the links here have been already provided in the various sections, and the aim is simply to collect all of the resources into one location for ease of access for the student.

\section{CONCLUSION}

In this paper we have presented an alternative way to provide information to both prospective and current Computer Science Honours students at The University of Newcastle (Australia). The Internet is increasingly becoming the most popular tool for research among students and academics alike. To best serve the new generation of students entering our universities we must adapt to provide them with information in a format that better appeals to their 'tech-savvy' nature. With the increase in the adoption of Learning Management Systems (LMS) among universities, we have been provided with a useful alternative, yet complimentary, tool for the delivery of program information to students. In investigating the usefulness of this approach we have developed two new Blackboard areas to Computer Science students at The University of Newcastle. The first area, the 'Computer Science Honours information area' is available to all undergraduate Computer Science students and is aimed at promoting the Honours program in a more attractive format that the standard university webpages. By providing information to students using a LMS we can directly target those students who have the potential to undertake a Computer Science Honours program in the future. Additionally, we are able to provide more flexible information delivery to these students, with the potential to spark interest in students who may not have previously considered undertaking such a program.

The 'Computer Science Honours project area' is reserved for students currently enrolled in the Honours program to offer specific support to these students during the course of the program. This LMS environment provides for more flexible delivery options to be presented to students currently undertaking the Computer Science Honours program. In particular, we can target commencing students to provide useful and important introductory material. The information presented in this area does appear in other locations on the main university website, however in a much more disjointed and less appealing format.

Both of the new Blackboard areas have been warmly received by academics in the Discipline of Computer Science and Software Engineering as they are filling a void in this area. Initial response to the new sites appears promising, with approximately $60 \%$ of enrolled students having viewed the material within the first month after its release. There has also been an apparent increase in the number of enquiries being made to the Honours program coordinator, with many of these students indicating that they are interested in knowing more about the program after viewing the Blackboard area.

More long term evaluation of these Blackboard areas will be conducted over coming years, according to the feedback we receive from students and the number of enrolments in the Computer Science Honours program. The next step in our project will be to expand the Blackboard area 'Computer Science Honours information area' to include information for the Software Engineering fourth year honours (final year project) students. There is a lot of overlap in the type of information that can be provided to these students, with that of the Computer Science Honours program, particularly in the areas of projects, scholarships and resources.

\section{ACKNOWLEDGMENT}

The authors would like to thank the Centre for Teaching and Learning at University of Newcastle, Australia for their support during the course of this project.

\section{REFERENCES}

[1] M. Prensky, "Digital natives, digital immigrants," On the Horizon, vol 9, no. 5, October 2001

[2] J. L. Frand, "The information-age mindset: Change in students and implications for higher education," Educause Review, pp. 15-24, September/October 2000.

[3] S. Bennett, K. Maton, and L. Kervin, "The 'digital natives' debate: A critical review of the evidence," British Journal of Educational Technology, vol. 39, no. 5, pp. 775-786, September 2008.

[4] G. E. Kennedy, T. S. Judd, A. Churchward, K. Gray, and K.-L. Krause, "First year student's experiences with technology: Are they really digital natives?" Australasian Journal of Educational Technology, vol. 24, no. 1, pp. 108-122, 2008.

[5] OECD, E-learning in tertiary education: Where do we stand? Education and Skills 2005, 2005.

[6] H. Coates, R. James, and G. Baldwin, "A critical examination of the effects of learning management systems on university teaching and learning," Ternary education and management, vol. 11, no. 1, pp. 1936, March 2005

[7] M. Prensky, "Part ii: Do they really think differently," On the Horizon, vol. 9, no. 5, October 2001

[8] D. Oblinger and J. Oblinger, Educating the Net Generation. EDUCAUSE, 2005, ch. Is It Age or IT: First Steps Toward Understanding the Net Generation, pp. 2.1-2.20.

[9] T. A. Pollack, "Using a course management system to improve instruction," in Proceedings of the Association of Small Computer Users in Education (ASCUE) Conference, North Myrtle Beach, SC, USA, June 8-12 2003.

[10] S. M. Johnstone, "Class participation and the whites of their eyes," Campus Technology, June 2002.

[11] L. S. J. Farmer, "Seven ways to blackboard," in Proceedings of the 68th IFLA Council and General Conference, Glasgow, Scotland, 1824 August 2002.

[12] Z. Yang and Q. Liu, "Research and development of web-based virtual online classroom," Computers and Education, vol. 48, no. 2, pp. 171-184, February 2007. 